\title{
Optimal Configuration of Photovoltaic-wind-storage Microgrid for Agricultural Irrigation in Mountainous Areas
}

\author{
Yangyang Zhang ${ }^{1 *}$ Bin Li $^{1}$ Youxiong Deng ${ }^{1}$ Chunjie Lian ${ }^{1}$ Jingde Wang ${ }^{1}$ \\ ${ }^{1}$ Guangxi Key Laboratory of Power System Optimization and Energy Technology, Guangxi University, Nanning, Guangxi Zhuang \\ Autonomous Region, 530004, China
}

\begin{abstract}
Water and electricity supply for irrigation is difficult in remote mountainous areas. This paper explores agricultural irrigation systems' integration mechanism, pumped storage power plants, and renewable power sources in mountainous areas to solve this problem. It establishes a microgrid power supply system with multiple complementary energy sources according to local conditions. By analyzing the load of agricultural irrigation in mountainous areas, the irrigation water consumption and electricity consumption are obtained. The capacity of pumped storage power stations, wind power, and photovoltaic power generation in the microgrid can be configured accordingly. They use the renewable power supply active power fluctuation rate index as a constraint and use the spectrum analysis method to calibrate the capacity configuration results. Finally, the scenic storage microgrid model is constructed and solved to minimize the microgrid's grid connection cost. The algorithm shows that the proposed capacity allocation method can meet the irrigation load demand and realize the microgrid's coordinated operation.
\end{abstract}

\section{Introduction}

Northern Guangxi Zhuang Autonomous Region is located in a remote area with many hills. The construction of power grid infrastructure is not in place, so agricultural production is greatly restricted. The region is rich in wind, solar, and water resources, conducive to renewable energy development and utilization, but the renewable power output is volatile and needs to be regulated by energy storage. It is an effective way to solve agricultural irrigation load in remote mountainous areas to establish a multi-energy complementary microgrid with wind power photovoltaic and energy storage according to local conditions. Making a reasonable capacity allocation to meet the load demand and improve the output fluctuation of renewable power has become a key issue for research. Many scholars at home and abroad have researched related content.

Many scholars in China and abroad have studied the related contents. On the one hand, domestic and foreign scholars have made the following studies for the microgrid's capacity configuration. The literature [1] established a probability density function model by analyzing scenic composite power samples' data. The rated charging and discharging power and the rated capacity of energy storage devices are obtained after calculation; the literature's objective [2] is the combined scenic storage system's optimal economy and the minimum output power fluctuation. The improved particle swarm algorithm was used to solve the objective function, and the capacity requirement of the corresponding pumped storage plant was derived.

On the other hand, the following studies have been conducted for load characteristics and demand problems. Literature [3] analyzed the water demand of islands and found that desalination systems are controllable. A power allocation strategy to coordinate desalination load demand, battery and diesel generator operation was proposed. The literature [4] modeled the cell load. A multi-objective nonlinear optimization model that simultaneously considers net present value cost, environmental penalty, and renewable energy utilization hours is proposed. The optimal equipment capacity of the cell microgrid was obtained by solving the optimization. In the literature [5], the cooling, heating, electricity, and domestic hot water loads of a small residential building in Dalian were simulated. The system equipment's optimal capacity configuration was obtained with the objective function of minimizing the total annual cost and annual $\mathrm{CO}_{2}$ and $\mathrm{NO}_{2}$ emissions.

The literature mentioned above has studied the capacity configuration problem and load characteristics and the scenic storage microgrid system's demand problems. However, there are fewer studies on renewable power capacity configuration when the energy storage capacity is known. Agricultural irrigation is a discontinuous load that must be satisfied during a specific period. Most of the existing microgrid operations are optimized with renewable power sources and energy storage units as controllable variables. Less attention is paid to the discontinuous timed long load demand. 
To this end, this paper first analyzes the characteristics of agricultural irrigation systems, pumped storage power plants, and wind power photovoltaic power generation in mountainous areas. The integration mechanism between the four is explored, and a multienergy complementary microgrid power supply system to meet the irrigation demand is constructed in this way. Each device's capacity is configured in terms of agricultural irrigation water demand and power demand, respectively. The configuration results are verified and corrected based on the spectrum analysis method. A microgrid for wind-wind and multi-energy complementary irrigation was constructed and simulated.

\section{Microgrid integration mechanism and structure}

\subsection{Microgrid integration mechanism and structure}

The mountain slopes in the Northern Guangxi Zhuang Autonomous Region are usually between $50-100 \mathrm{~m}$ in height, with a natural high drop. Local orchards need frequent irrigation. In summer, crop transpiration is strong at noon, so irrigation is suitable before 10:00 or after 16:00; in winter, the temperature is lower in the morning and evening, so irrigation is proper between 10:00-15:00. Typical irrigation schemes for citrus orchards are shown in Table 1.

Table 1 Year-round irrigation system for citrus orchards

\begin{tabular}{c|c|c|c|c|c|c|c|c|c|c|c|c}
\hline Month & 1 & 2 & 3 & 4 & 5 & 6 & 7 & 8 & 9 & 10 & 11 & 12 \\
\hline Irrigation cycle(days) & \multicolumn{3}{|c|}{$20-25$} & \multicolumn{7}{c|}{$7-10$} & \multicolumn{3}{c|}{$5-7$} & $15-20$ & $22-25$ \\
\hline Irrigation periods & \multicolumn{3}{|c|}{$10: 00-15: 00$} & \multicolumn{7}{c|}{$0: 00-10: 00$ and16:00-24:00 } & \multicolumn{2}{c}{$10: 00-15: 00$} \\
\hline Number of irrigation & 2 & 3 & 2 & 9 & 2 & 11 & 14 & 19 & 14 & 11 & 3 & 6 \\
\hline Sub-irrigation volume $\left(\mathrm{m}^{3}\right)$ & 39.6 & 61.8 & 71.5 & 75.6 & 66.5 & 73.5 & 74.3 & 79.3 & 76.3 & 74.9 & 62.4 & 77.6 \\
\hline Irrigation flow $\left(\mathrm{m}^{3} / \mathrm{h}\right)$ & 7.92 & 12.3 & 14.3 & 15.1 & 13.3 & 14.7 & 14.8 & 15.2 & 15.1 & 14.9 & 12.4 & 15.1 \\
\hline
\end{tabular}

As seen in Table 1, the average daily irrigation hours of orchard irrigation are $7.5 \mathrm{~h}$, accounting for $31.3 \%$ of the whole day. The annual average irrigation days is 34 days, which accounts for $9 \%$ of the yearly days. The comprehensive utilization rate of water conservancy facilities such as pumping is less than 5\%. Suppose you build a cistern at the top of the mountain as the upper reservoir, another cistern at the mountain's foot as the lower reservoir. The whole set of facilities can be operated as a small pumped storage power station using the vacant water conservancy facilities as pumping units and adding turbines and generators.

Northern Guangxi Zhuang Autonomous Region area is rich in light and wind resources. Wind and solar energy can output a large amount of electricity for pumping irrigation. On the one hand, renewable power generation is influenced by the environment and has a large fluctuation. On the other hand, there is sufficient sunshine in Northern Guangxi Zhuang Autonomous Region during the daytime in summer, and the wind speed is low at night. At the same time, the irrigation time is concentrated in the evening. In winter, the daytime sunshine is poor, the wind speed is high at night, and the irrigation time is focused at noon. There is a contradiction between renewable power generation time and irrigation power consumption time. A pumped storage power station can regulate and store energy, control renewable power output and alleviate the contradiction between renewable power generation and the irrigation power consumption time. Therefore, based on the irrigation system, the microgrid can be built on a hill or slope. Its architecture is shown in Figure 1.

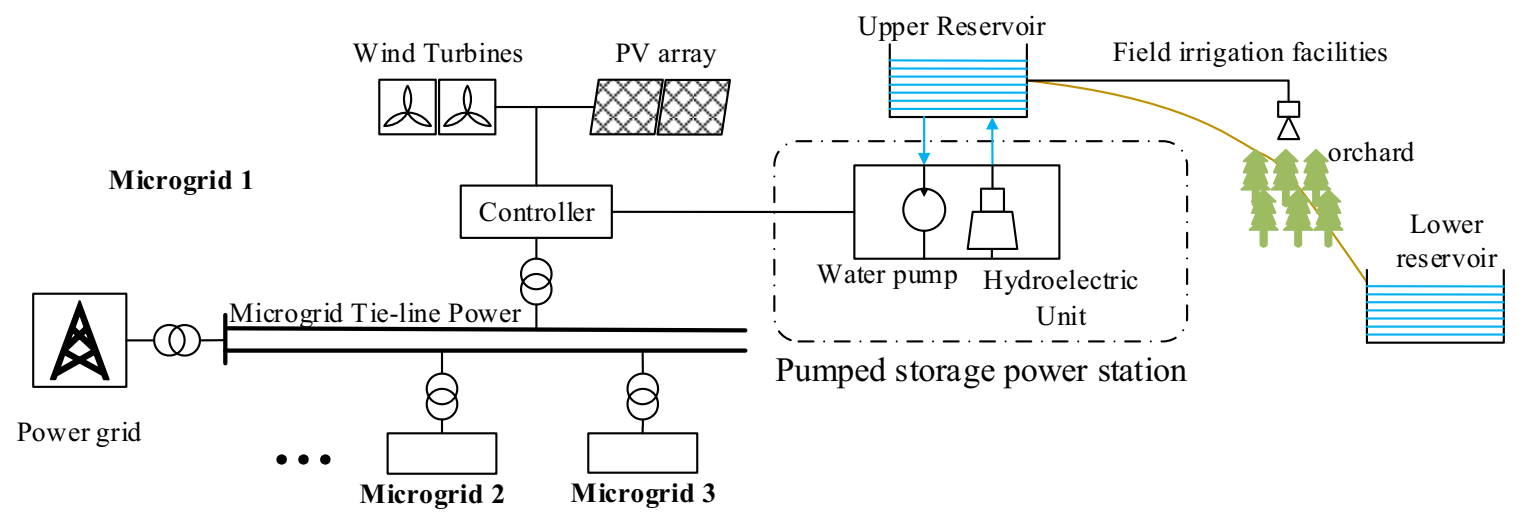

Figure 1. System structure diagram 


\subsection{Capacity configuration method}

The microgrid's capacity configuration needs to consider two principles.(1)First of all. It should meet the demand for irrigation water and electricity. The demand for irrigation water determines the hilltop reservoir's size and

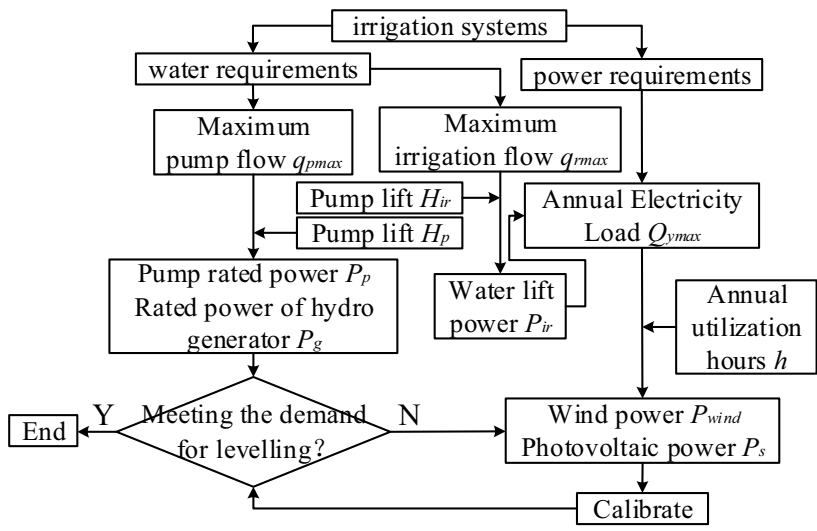

(a) Capacity Configuration the installed capacity of small pumped storage power plants. (2) Secondly, it should minimize the negative impact of distributed power sources' volatility and intermittency on the microgrid system's operation. Thus, small pumped-storage power plants' regulation capacity determines wind and PV power plants' installed capacity.

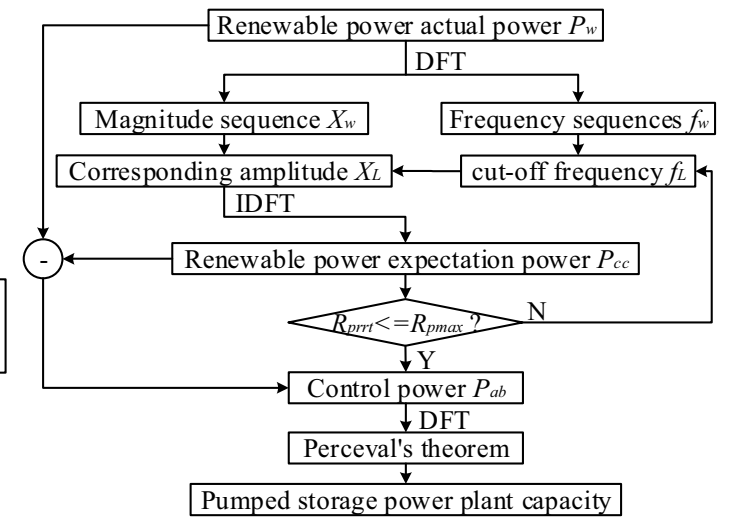

(b) Calibration Process

Figure 2. Capacity allocation flow chart

Lift and water flow parameters are the determining factors for pump selection. Pumped storage power plants are configured using water volume, i.e., reservoir capacity, pumping flow, and turbine flow are calculated based on irrigation regime and irrigation volume.

Configuration of wind and PV plant capacity according to electricity demand.

$$
H_{h}=W / G
$$

where $H_{h}$ is the annual utilization hours of renewable power. $W$ is the annual electricity consumption of irrigation. $G$ is the rated power of renewable energy.

Renewable energy power expectations need to meet power volatility requirements, and the expression of fluctuation rate is:

$$
R_{p r r T}=\frac{P_{\max T}-P_{\min T}}{P_{n}} \times 100 \%
$$

where $R_{p r r T}$ is the power volatility in time period $T . P_{n}$ is the rated power of renewable power supply. $P_{\max T}$ and $P_{\min T}$ are respectively the maximum power and minimum power in time period $T$.

DFT can convert renewable power from time domain to frequency domain, which is expressed as follows:

$$
Y(n)=\sum_{k=0}^{N-1} y_{k} \cdot e^{\frac{-2 \pi j n k}{N}}
$$

where $y_{k}$ is the time-domain signal. $Y(n)$ is the frequency domain signal. $N$ is the total number of samples in the time domain. $k$ is the sampling sequence number in the time domain. $n$ is the sampling sequence number in the frequency domain,

The expected power $P_{c c}$ of the renewable power source meeting the requirements of power volatility can be obtained, and the control power $P_{a b}$ can be calculated:

$$
P_{a b}=P_{c c}-P_{w}
$$

where $P_{w}$ is the actual power of the renewable power source.

By DFT of the control power $P_{a b}$, the energy demand of each frequency band can be obtained by Parceval theorem, thus the capacity of the pumped storage power station can be obtained:

$$
P\left(f_{1}, f_{2}\right)=\sqrt{\sum_{f_{1}}^{f_{2}}\left|P_{a b}(f)\right|^{2}}
$$

where $P\left(f_{1}, f_{2}\right)$ is the control capacity defined within the frequency range $\left[f_{1}, f_{2}\right]$.

\subsection{Wind-solar microgrid model}

2.3.1 Objective function Taking the minimum operating cost of microgrid as the aim function:

$$
F_{\text {E.min }}=\sum_{t=1}^{T}\left[C_{r l}^{t} P_{r l}^{t}+C_{s}^{t} P_{s}^{t}+C_{\text {wind }}^{t} P_{\text {wind }}^{t}\right]
$$

where $C_{r l}^{t}$ is the purchase/sale price of electricity from the microgrid to the larger grid. $C_{s}^{t}$ is the cost of PV power generation. $C_{\text {wind }}^{t}$ is the cost of wind power generation. $P_{r l}^{t}$ is the exchange power of the microgrid tie-line power. Define $P_{r l}^{t}>0$ as the power supply from the external grid to the microgrid system, and vice versa, the microgrid sells electricity to the external grid. $P_{s}^{t}$ is the PV power. $P_{\text {wind }}^{t}$ is the wind power. The day is divided into 96 equal time periods, and the relevant period is denoted by " time period $t$ ", $t=1,2,3 \cdots 96$. 
2.3.2 Binding Conditions Fit the power-water flow characteristics curve of the pump using the least-squares method. The power-water flow characteristics of the water pump are expressed as:

$$
P_{p}^{t}=a_{p}\left(q_{\mathrm{p}}^{t}\right)^{2}+b_{p} q_{p}^{t}+c_{p}
$$

where $a_{p}, b_{p}, c_{p}$ are the pumping unit's power factor. $q_{\mathrm{p}}^{t}$ is the pumping flow rate of the pumping unit $P_{p}^{t}$ is the pumping power of the pumping team.

The water lift power-water flow characteristic can be expressed as:

$$
P_{i r}^{t}=a_{i r}\left(q_{i r}^{t}\right)^{2}+b_{i r} q_{i r}^{t}+c_{i r}
$$

where $a_{i r}, b_{i r}, c_{i r}$ are the power coefficient of the waterlift unit. $q_{i r}^{t}$ are the irrigation flow of the water-lift. $P_{i r}^{t}$ is the power of the water-lift.

The output power of a wind turbine is related to the wind speed. Expressed by piecewise function:

$$
P_{\text {wind }}^{t}=\left\{\begin{array}{cc}
0 & v^{t} \leq v_{\text {in }}, v^{t} \geq v_{\text {out }} \\
P_{r} \frac{v^{t}-v_{\text {in }}}{v_{r}-v_{\text {in }}} & v_{\text {in }} \leq v^{t} \leq v_{r} \\
P_{r} & v_{r} \leq v^{t} \leq v_{\text {out }}
\end{array}\right.
$$

where $P_{r}$ is the rated power. $v^{t}$ is the actual wind speed. $v_{r}$ is the rated wind speed. $v_{i n}$ is the cut-in wind speed. $v_{\text {out }}$ is the cut-out wind speed.

PV power decreases with increasing temperature and increases with increasing light intensity:

$$
P_{\mathrm{s}}^{t}=\eta S I^{t}\left(1-0.005\left(t_{\mathrm{o}}^{t}+25\right)\right)
$$

where $\eta$ is the conversion efficiency of the light source. $S$ is the photovoltaic panel area. $I^{t}$ is the light intensity. $t_{\mathrm{o}}^{t}$ is the ambient temperature.

The power generation characteristics of a pumped storage power station belonging to the reverse process of pumping and its power generation-water flow characteristics can be expressed as:

$$
P_{g}^{t}=a_{g}\left(q_{g}^{t}\right)^{2}+b_{g} q_{g}^{t}+c_{g}
$$

where $a_{g}, b_{g}, c_{g}$ are the power coefficients of the generator set; $q_{g}^{t}$ is the generation water flow rate of the hydro-generator. $P_{g}^{t}$ is the generation power of the generator set.

$$
\begin{gathered}
P_{\mathrm{s}}^{t}+P_{\text {wind }}^{t}+P_{g}^{t}-P_{p}^{t}-P_{i r}^{t}+P_{r l}^{t}=0 \\
r^{t+1}=r^{t}-\left(q_{g}^{t}-q_{p}^{t}\right)-q_{i r}^{t}
\end{gathered}
$$

where $r$ is the reservoir capacity.

$$
\sum_{t=t_{1}}^{t=t_{2}} q_{i r}^{t}=Q
$$

where $t_{1}$ and $t_{2}$ are the beginning and ending time of irrigation, respectively. $Q$ is the total amount of irrigation on the day.

$$
q_{g}^{t} q_{p}^{t}=0
$$

And the states of power generation and water pumping are opposites.

Besides, the power of wind turbine systems, PV array and microgrid tie-line, the water flow rate of lifters pumping, and turbine generators are constrained by the corresponding upper and lower limits.

\section{Case study}

A mountainous orchard $\left[25.394^{\circ} \mathrm{N}, 110.414^{\circ} \mathrm{E}\right]$ is used as the research object to construct a microgrid. The orchard is planted with citrus crops, with an area of 3.34ha. Calculate crop water requirements and establish the irrigation system. The annual water consumption of the irrigation system is $7121 \mathrm{~m}^{3}$, and the annual electricity consumption is $5784.7 \mathrm{kWh}$.

According to the irrigation system, The maximum irrigation amount is less than $80 \% 80 \mathrm{~m}^{3}$. The floor space and construction cost also influence the reservoir capacity. Under the comprehensive consideration of the above factors, the hilltop reservoir's storage capacity is $50 \mathrm{~m}^{3}$. The ability of a pumped-storage power plant is configured according to the water demand. Wind power and photovoltaic power generation are configured according to the power demand. The configuration results are shown in Table 2.

The wind power and PV power data of a typical day are selected for simulation. The data sampling interval is $1 \mathrm{~min}$. The power fluctuation rate within $5 \mathrm{~min}$ is not more than $10 \%$. It is the standard, and the expected output value corresponding to the load fluctuation rate requirement is obtained by recursive calculation.

Table.2 Basic parameters of equipment

\begin{tabular}{c|c|c|c|c}
\hline Type & Power $/ \mathrm{kW}$ & Type & Power $/ \mathrm{kW}$ & Flow $/\left(\mathrm{m}^{3} / \mathrm{h}\right)$ \\
\hline Wind Power generator & 5.8 & Hydro Generator & 11 & 17 \\
\hline PV power generator & 6.5 & Water Pump & 11 & 15 \\
\hline$/$ & $/$ & Water Lift & 1.5 & 19 \\
\hline
\end{tabular}

power supply, and the microgrid can operate in coordination.
The calculation shows that the pumped storage power station's capacity can meet the suppression of renewable 


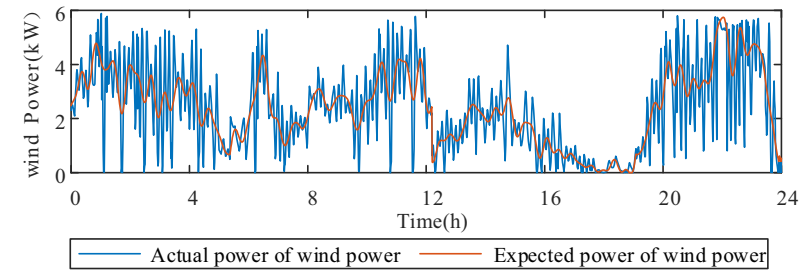

(a) Wind power of pumped storage power station before and after regulation

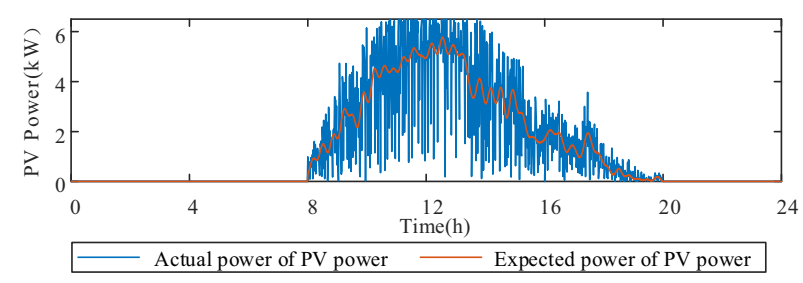

(b) $\mathrm{PV}$ power of pumped storage power station before and after regulation

Figure 3 Renewable power before and after regulation of Pumped Storage Power Station

\section{Conclusion}

This paper firstly constructs a scenic storage microgrid to meet the agricultural irrigation in mountainous areas. A method of microgrid equipment capacity configuration using irrigation water consumption and electricity consumption is proposed, and the configuration results are calibrated according to the spectrum analysis method. Next, a microgrid model is established and solved with the objective of minimum grid connection cost. The reasonableness of the capacity allocation results and the coordination of microgrid operation are verified by analyzing calculation cases, which provides new ideas for equipment selection and investment planning of multi-energy complementary microgrids.

\section{References}

1. Yao T, Zhang X, Wu X, Li Z, Ma C. (2016) Energy Storage Capacity Configuration to Stabilize the Short Composite Power Fluctuation for Wind-Solar Complementary Hybrid. System Power System and Clean Energy, 32(10): 120-127.

2. Dai J, Dong H,(2019) Research on the Capacity Optimization of the Wind-Solar Hybrid Power Supply System Based on Pumped Storage Power Station. System Power System and Clean Energy, 35(06): 76-82.

3. Zhang J, Yu L, Liu N, Xiao R.(2014) Capacity Configuration Optimization for Island Microgrid with Wind/Photovoltaic/Diesel/Storage and Seawater Desalination Load. Transactions of China Electrotechnical Society, 29(02): 102-112.

4. Sun C, Ju S, Chen B, Guo J, Li T.(2021). Optimal design of residential type micro-grid power supply system with multi-energy complementary. Electrical Measurement \& Instrumentation, 29(02): 102-112.

5. Ding S, Zhou B, Hu B. (2021) Design Optimization of Small Distributed Energy System based on NSGA-II algorithm. Acta Energiae Solaris Sinica,42(01): 438-445.

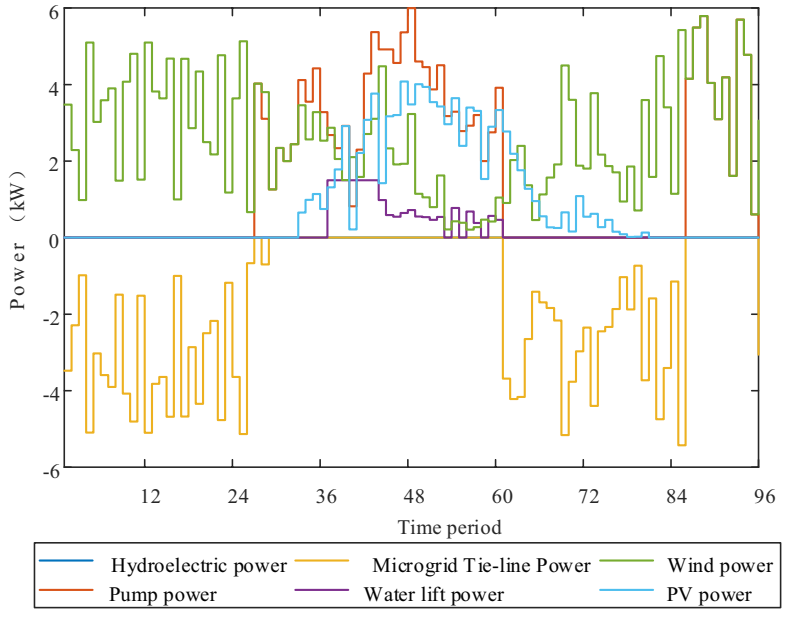

Figure 4 Microgrid operation curve on windy and sunny days in winter 